\title{
Simple Niobium Catalysts Applied in Reflux and Ultrasound-Assisted Systems for Biofuel Synthesis
}

\author{
Bruno H. Arpini, ${ }^{a}$ Diana C. Cubides-Román, ${ }^{a}$ Clara L. Javarini, ${ }^{a}$ Milena C. de Araújo, ${ }^{a}$ \\ Geraldo F. David, ${ }^{a}$ Reginaldo B. dos Santos, ${ }^{a}$ Wanderson Romão, ${ }^{a, b}$ Alvaro C. Neto ${ }^{a}$ and \\ Valdemar Lacerda $\mathrm{Jr}$. ${ }^{\odot * a}$
}

${ }^{a}$ Laboratório de Pesquisa e Desenvolvimento de Metodologias para Análise de Petróleos (LabPetro), Universidade Federal do Espírito Santo (UFES), Av. Fernando Ferrari, 514, Goiabeiras, 29075-910 Vitória-ES, Brazil

${ }^{b}$ Instituto Federal do Espírito Santo (IFES), Av. Ministro Salgado Filho, Soteco, 29106-010 Vila Velha-ES, Brazil

\begin{abstract}
Using niobium compounds as heterogeneous catalysts in biodiesel production is a promising methodology from economic and environmental viewpoints. However, the application of niobium catalysts still is a challenge due to the high temperatures and pressures for moderate biofuel yields. Therefore, easily handled and applied materials have been developed to optimize biofuel production, which is the goal of this study. $\mathrm{Nb}_{2} \mathrm{O}_{5}$ and ammonium niobium oxalate (AmNO) were activated in reflux and ultrasound-assisted system. $\mathrm{Nb}_{2} \mathrm{O}_{5}$ showed better activity under reflux, using methanol. The characterizations conclude that the Lewis-acid sites are determinant for higher conversion rather than surface area. AmNO has better activity also in the reflux system at $70{ }^{\circ} \mathrm{C}$, against $170{ }^{\circ} \mathrm{C}$ for $\mathrm{Nb}_{2} \mathrm{O}_{5}$, reaching above $70 \%$ conversion. In addition, reactions in ultrasound-assisted systems are also appealing due to the lower time and temperature, with conversion rates above $40 \%$. Both catalysts showed interesting results under milder conditions than those in the literature.
\end{abstract}

Keywords: ammonium niobium oxalate, niobium pentoxide, biodiesel, heterogeneous catalysis

\section{Introduction}

Biodiesel is a biodegradable and clean-burning fuel that is considered a viable alternative to current petroleumderived diesel. ${ }^{1,2}$ Commercial biodiesel is synthesized via liquid base-catalyzed transesterification of $\mathrm{C}_{14}-\mathrm{C}_{20}$ triacylglyceride components of lipids with $\mathrm{C}_{1}-\mathrm{C}_{2}$ alcohols, into fatty acid methyl esters (FAMEs), combined with glycerol as a potentially valuable by-product. ${ }^{1}$ Biodiesel production via transesterification requires a catalyst (homogeneous or heterogeneous) to obtain equilibrium in a practical manner. ${ }^{3}$ Acid-based homogeneous catalysts, such as $\mathrm{H}_{2} \mathrm{SO}_{4}$ and $\mathrm{HCl}$ operate at high temperature, are difficult to recycle, corrosive in nature and take more time during biodiesel synthesis. Although alkaline-based catalysts such as $\mathrm{KOH}$ and $\mathrm{NaOH}$ are faster, they react with free fatty acids to form undesirable products (soap), in turn increasing $\mathrm{pH}$ of FAMEs and thus requiring expensive separation. ${ }^{4}$

*e-mail: vljuniorqui@gmail.com
Heterogeneous catalysts can lower the cost of production and make it sustainable. This is because when the catalyst is not in the same phase as reactants/products, product separation and catalyst recovery are quite easy. The development of solid base catalysts has been widely described in the literature. ${ }^{3-6}$ However, the physical and structural properties of the catalyst need to be adequately formulated during catalyst preparation to obtain good results.? Several studies have proved the technical feasibility and the environmental and economic benefits of biodiesel production via heterogeneous acid-catalyzed transesterification. ${ }^{3,8,9}$

The niobium oxides and their compounds have a large variety of roles in catalysis, such as promoter, support, redox and acid properties. ${ }^{10,11}$ Thus, niobium-containing materials have been proposed as effective catalysts in the dehydration of alcohols, oxidation, hydrolysis, alkylation, esterification, photocatalysis and isomerization. ${ }^{12-21}$ Ammonium niobium oxalate (AmNO, $\left.\mathrm{NH}_{4}\left[\mathrm{NbO}\left(\mathrm{C}_{2} \mathrm{O}_{4}\right)_{2}\left(\mathrm{H}_{2} \mathrm{O}\right)_{\mathrm{x}}\right] \cdot \mathrm{nH}_{2} \mathrm{O}\right)$ is used as a niobium precursor in the preparation of functionalized materials, including ceramics, optical lenses, high purity 
niobium oxides, tin films and catalysts. Compared with $\mathrm{NbCl}_{5}$, this niobium salt is cheap, easy to handle and not sensitive to air or moisture. ${ }^{12,13}$ Its relatively low toxicity allied to its solubility in water was used by Mendes et al. ${ }^{12}$ to develop the synthesis of bis(indolyl)methanes using water or glycerol as solvent, obtaining excellent yields with easy reuse of the catalyst.

Aranda et al. ${ }^{22}$ evaluated the influence of alcohol/fatty acid molar ratio (methanol or ethanol), water and catalyst concentrations, and temperature in the esterification of palm oil fatty acids using different catalysts, including various granularities of niobium $(\mathrm{V})$ oxide $\left(\mathrm{Nb}_{2} \mathrm{O}_{5}\right)$. Guinhos et al. ${ }^{23}$ found that $\mathrm{Nb}_{2} \mathrm{O}_{5} / \mathrm{H}_{3} \mathrm{PO}_{4}$ and $\mathrm{Nb}_{2} \mathrm{O}_{5} / \mathrm{H}_{2} \mathrm{SO}_{4}$ as catalysts for the esterification showed better conversion (57\%) than $\mathrm{Nb}_{2} \mathrm{O}_{5} \cdot \mathrm{xH}_{2} \mathrm{O}$ and $\mathrm{Nb}_{2} \mathrm{O}_{5}(32-36 \%)$, using $10 \mathrm{~g}$ of soybean fatty acids, $4 \mathrm{~g}$ of $\mathrm{MeOH}, 1 \mathrm{~h}, 160{ }^{\circ} \mathrm{C}$.

Besides the catalyst choice, the analysis of different reactor configurations and their mixture methods are important tasks. The immiscibility of the reactants is a concern in biodiesel production and intense agitations are necessary to minimize mass-transfer limitations. ${ }^{24}$ Ultrasound-assisted synthesis is a green, rapid, economic, environmentally friendly and safe technique employed to accelerate chemical processes. ${ }^{25}$ The chemical and physical effects of ultrasound on the transesterification reaction are explained by the radicals that are produced during the collapse of the bubble; that phenomenon induces and accelerates the chemical reaction in the bulk medium. In addition, the microturbulence generated due to radial motion of bubbles creates an intimate mixing of the immiscible reactants, increasing the interfacial area between the reactants and giving faster reaction kinetics. ${ }^{26}$ As a consequence, the increase in reaction kinetics produces a high yield at low alcohol to oil molar ratios and reduction in reaction temperature and time..$^{25-27}$ The application of ultrasound in homogeneously catalyzed biodiesel production processes has been widely investigated ${ }^{26-29}$ and also the effects of ultrasound when solid catalysts are used. ${ }^{24,30-32}$

Some published works use niobium compounds as catalysts to produce biodiesel, ${ }^{23,33-36}$ but none of them under ultrasound-assisted reaction conditions; for this reason, the objective of this research was to test different oil sources and niobium(V) oxide and $\mathrm{AmNO}$ as catalysts for biodiesel production with reflux and ultrasound-assisted reaction.

\section{Experimental}

\section{Niobium pentoxide reactions}

The niobium pentoxide catalyst $\left(\mathrm{Nb}_{2} \mathrm{O}_{5} \cdot \mathrm{xH}_{2} \mathrm{O}\right)$ HY-340, donated by Companhia Brasileira de Metalurgia e Mineração (CBMM), was calcined in a mufla Microprocessed-Q318M for $3 \mathrm{~h}$ in a ceramic crucible, under normal atmosphere. Calcination temperatures were 115 and $300^{\circ} \mathrm{C}$. The catalyst was used immediately after calcination. The transesterification reactions were performed in a round-bottom flask containing $1.5 \mathrm{~g}$ of methanol or ethanol (> 99\%), $0.5 \mathrm{~g}$ of vegetable oil (peanut, sunflower, canola, corn and soybean). The catalyst in ratio of 20 or $100 \%$ of the oil mass and also a polar aprotic solvent (dimethyl sulfoxide, DMSO), mass ratios were previously studied by dos Santos et al. ${ }^{37}$ applying niobium pentoxide in esterification reactions of oleic acid with methanol. For the reflux system, the temperature of $170{ }^{\circ} \mathrm{C}$ was maintained for $48 \mathrm{~h}$ under constant stirring at $400 \mathrm{rpm}$. All solvents were properly distilled.

For the ultrasonic-assisted system, a frequency of $42 \mathrm{kHz}$ and a water bath temperature at $60^{\circ} \mathrm{C}$ (CRISTOFOLI) was used. Thermal treatment of $115^{\circ} \mathrm{C}$ in the catalyst and the same mass proportions of oil and methanol were used with reaction times of 2, 4 and $6 \mathrm{~h}$.

\section{Ammonium niobium oxalate reactions}

The transesterification reactions were made under reflux using AmNO catalyst (also donated by CBMM). However, previous thermogravimetric analysis indicated that temperatures above $70{ }^{\circ} \mathrm{C}$ must be avoided, which is going to be discussed in the results. Thus, the catalyst was used without any thermal treatment. First, a test under reflux was performed for $2 \mathrm{~h}$ and after a positive result, other reactions were performed for 4, 24 and $48 \mathrm{~h}$, under constant stirring at $400 \mathrm{rpm}$, with mass proportions of the catalyst of 20 and $100 \%$.

Ultrasound-assisted reactions using AmNO as catalyst, ethanol or methanol, and soybean, canola, or linseed oils were carried out under the same mass proportions of catalyst applied in the reflux reactions. The reaction conditions and solvent were the same as those used for $\mathrm{Nb}_{2} \mathrm{O}_{5} \cdot \mathrm{nH}_{2} \mathrm{O}$.

\section{${ }^{1} \mathrm{H}$ NMR analysis}

All obtained products were isolated using the multiple extraction method with distilled water and hexane and further analysis by thin layer chromatography (TLC). Blank experiments were performed for all tests using AmNO and $\mathrm{Nb}_{2} \mathrm{O}_{5} \cdot \mathrm{nH}_{2} \mathrm{O}$ as catalysts. After total solvent degassing, the product was prepared for ${ }^{1} \mathrm{H}$ nuclear magnetic resonance (NMR) analysis to determine the conversions of vegetable oils into biofuel. The equipment was a Varian $300 \mathrm{MHz}$ and 
$5 \mathrm{~mm}$ broadband ${ }^{1} \mathrm{H} / \mathrm{X} / \mathrm{D}$ probe. The solvent used for all analyses was $\mathrm{CDCl}_{3}$. The chemical shifts $(\delta)$ were plotted in parts per million ( $\mathrm{ppm}$ ) relative to the internal standard, $1 \%$ TMS (tetramethylsilane).

The biodiesel conversion was obtained adapting the method reported by Gelbard et al. ${ }^{38}$ Thus, expressions relating the area of integration of double-doublet signals (dd) of the triacylglyceride of the vegetable oil with $\delta$ at approximately $4.2 \mathrm{ppm}(\mathrm{Ao})$ to the singlet (s) at $3.6 \mathrm{ppm}$ and a quadruplet (q) at about $3.75 \mathrm{ppm}$ for the $\mathrm{CH}_{2}$ of the biofuel $(\mathrm{Ab})$ were observed, as shown in Figures $\mathrm{S} 1$ and S2 (in the Supplementary Information (SI) section). Some examples are available in the SI section. From this, the expressions for methyl biodiesel production (1) and for ethyl biodiesel production (2) are:

Conversion ME $(\%)=\frac{3 \times \mathrm{Ab}}{(3 \times \mathrm{Ab})+(2 \times \mathrm{Ao})} \times 100$

Conversion $\mathrm{EE}(\%)=\frac{\mathrm{Ab}}{\mathrm{Ab}+\mathrm{Ao}} \times 100$

\section{Thermogravimetry analysis (TGA)}

To obtain the mass loss data on heating, TGA equipment from TA Instruments model SDTQ600 was used. The compounds were weighed in an alumina crucible and subjected to a heating rate of $10{ }^{\circ} \mathrm{C} \mathrm{min}-1$ from 25 up to $800^{\circ} \mathrm{C}$, in an air atmosphere.

Infrared analysis

Infrared (IR) analyses were used to obtain vibrational information of the catalyst's chemical bonds. An ABB FTIR spectrophotometer model FTLA2000 was used for the acquisition, using the PIKE FTLA MIRacle ${ }^{\mathrm{TM}}$ accessory, an ATR (attenuated total reflection) accessory.

A study for the acid sites' characterization was performed for all catalysts by the chemisorption of pyridine. First, niobium pentoxide was purged with argon several times for surface cleaning. Then, the cleaned pre-catalyst was calcined at 115 and $300{ }^{\circ} \mathrm{C}$. Pyridine was adsorbed on a known mass of the catalyst $(20 \mathrm{mg})$ by contact with a dilute solution in $\mathrm{CHCl}_{3}$ and successive degassing at beam temperature under vacuum. Further IR analyses were performed in the FTIR spectrophotometer, with the dry catalysts. The obtained data were analyzed and the assigned bands fitted by Lorentz model and then a relative ( 0 to 1 ) area comparison was performed.

\section{Brunauer-Emmett-Teller (BET) analysis}

Specific area analysis was conducted using the $\mathrm{N}_{2}$ adsorption/desorption isotherms at $77 \mathrm{~K}$, with a Quantachrome Autosorb-1 instrument. The specific surface area values were determined by the Brunauer-EmmettTeller (BET) method ${ }^{39}$ using relative pressures $\left(\mathrm{P} / \mathrm{P}_{0}\right)$ in the range of $0.05-0.31$ and the pore size distributions were computed using the nonlocal density functional theory approach. ${ }^{40}$

\section{X-ray diffraction}

The X-ray diffraction (XRD) analyses were carried out at room temperature $\left(23{ }^{\circ} \mathrm{C}\right)$ in an $\mathrm{X}$-ray powder diffractometer Shimadzu XRD-6000, with radiation $\mathrm{Cu} \mathrm{K \alpha}$ $(\lambda=1.5418 \AA)$, with diffraction angle $(2 \theta)$ ranging from 10 to $80^{\circ}$ in $1^{\circ}$ intervals, voltage of $40 \mathrm{kV}$ voltage and current at $30 \mathrm{~mA}$ current. The obtained diffractograms were compared and analyzed using JCPDS (Joint Committee on Powder Diffraction Standards) of the International Center for Diffraction Data, available in PCPDFWIN software, version 2.3.

\section{Results and Discussion}

TGA of niobium pentoxide determined the thermal stability of the catalyst and allowed the determination of the number of water molecules per mol of $\mathrm{Nb}_{2} \mathrm{O}_{5}$ (Figure $\mathrm{S} 3$ in the SI section). The number of water molecules is directly linked with the behavior of the niobium pentoxide acting as a Lewis acid or as Brønsted-Lowry acid (leading to different catalytic pathways as showed in Scheme S1 in the SI section), as described by Nowak and Ziolek. ${ }^{41}$ The use of chemical calculations of catalyst mass losses allowed us to determine the molecular formula of hydrated niobium pentoxide. The obtained molecular formula is $\mathrm{Nb}_{2} \mathrm{O}_{5} \cdot 1.8 \mathrm{H}_{2} \mathrm{O}$.

IR analyses were performed to verify the loss of adsorption and hydration water as a result of increasing the temperature (Figure 1). The analyses confirmed the disappearance of the wide bands with the increase in the temperature at approximately $3200 \mathrm{~cm}^{-1}$ referring to the stretching of the $\mathrm{O}-\mathrm{H}$ bond, and showed that at higher temperatures, the Brønsted-Lowry acid character is less accentuated than the Lewis analogues.

All $\mathrm{Nb}_{2} \mathrm{O}_{5}$ catalysts showed bands attributed to acid sites by pyridine chemisorption investigation, as presented in Figure 2. There are Lewis-acid sites PyL (LAS) at $1440 \mathrm{~cm}^{-1}$, both LAS-PyL and Brønsted-acid sites $\mathrm{PyH}^{+}$ (BAS) at $1485 \mathrm{~cm}^{-1}$ and BAS at $1542 \mathrm{~cm}^{-1}$, but the $\mathrm{PyH}^{+}$ band at BAS was not easy to observe (the possible 

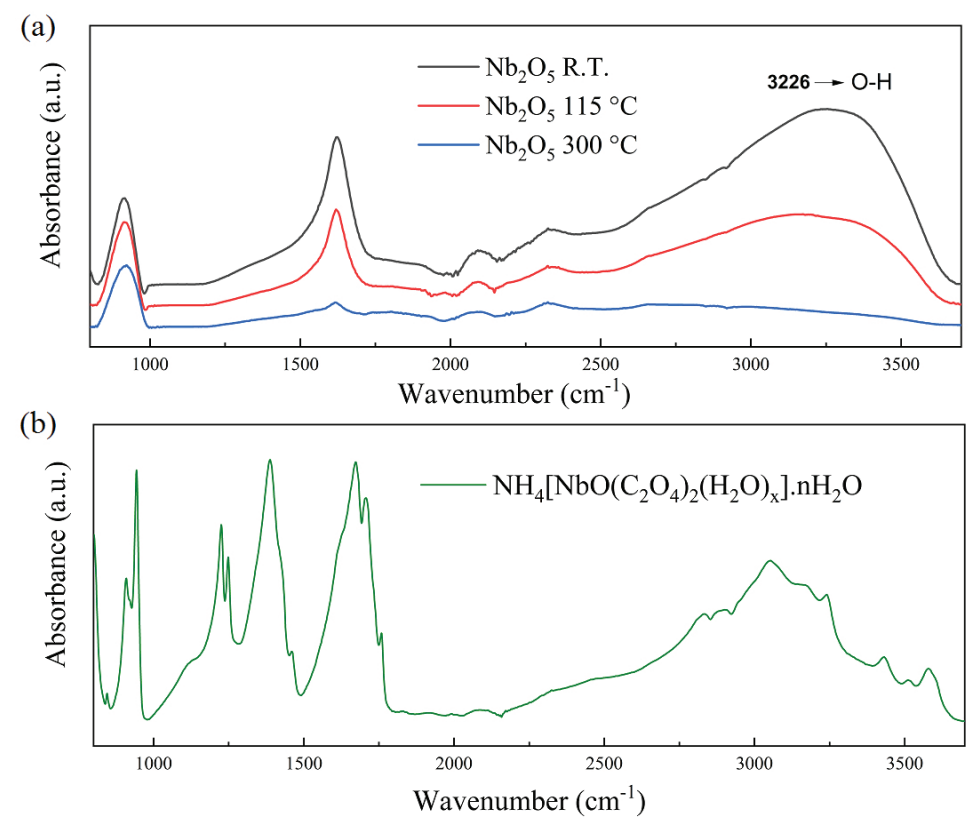

Figure 1. FTIR analysis of (a) niobium pentoxide and (b) ammonium niobium oxalate.

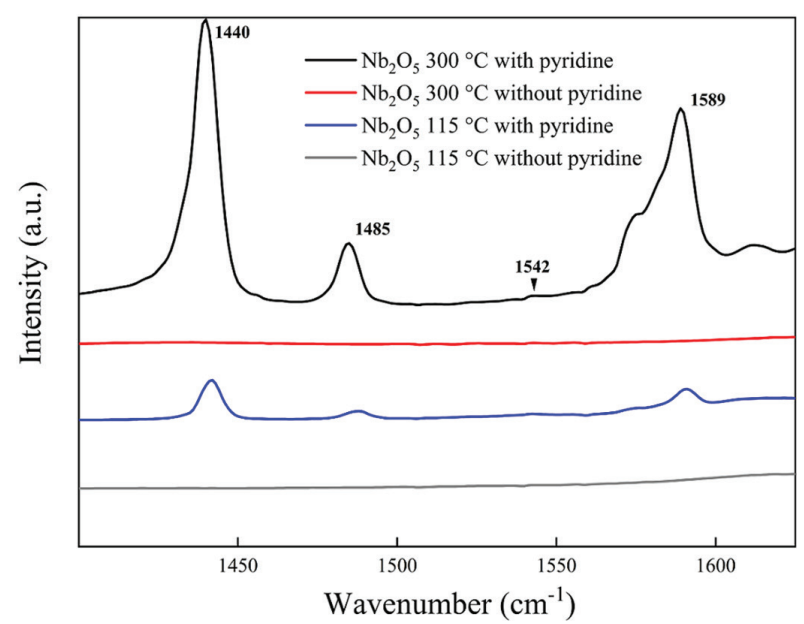

Figure 2. FTIR analysis of pyridine adsorption on $\mathrm{Nb}_{2} \mathrm{O}_{5} \cdot 1.8 \mathrm{H}_{2} \mathrm{O}$ catalyst calcined under different temperatures to determine acid sites.

reason is the long time of heating treatment). Moreover, the integration areas of the LAS and LAS + BAS bands (Table 1) made it possible to confirm that LAS increases as the calcination temperature increases, as expected. ${ }^{42}$

The specific surface areas for all catalysts were obtained from the BET analysis (Table 1). From this, it was observed that when the catalyst is heated to $115{ }^{\circ} \mathrm{C}$, there is an increase in surface area, it may occur due to the loss of adsorbed water (about $8 \% \mathrm{~m} / \mathrm{m}$ ), as presented in Figure S3 in the SI section. Meanwhile, when heated up to $300{ }^{\circ} \mathrm{C}$, the catalyst has shown a significant decrease in its surface area, probably due to a transition from an amorphous to a crystalline phase.

Moreover, it is possible to observe from the XRD analyses (Figure 3a) that the formation of well-defined peak signals was seen when the niobium pentoxide was calcined for $3 \mathrm{~h}$ at $300^{\circ} \mathrm{C}$, corroborating the BET analysis. Furthermore, following the diffraction pattern described in the JCPDS database (number 37-1468), the morphology of our catalyst after thermal treatment at $300^{\circ} \mathrm{C}$ is hexagonal. It was discussed by Rade et al..$^{43}$ that with a heat treatment at $300{ }^{\circ} \mathrm{C}$, the niobium pentoxide still leads to an amorphous solid profile. The probable divergence in observations is that different times in the calcination of $\mathrm{Nb}_{2} \mathrm{O}_{5} \cdot \mathrm{xH}_{2} \mathrm{O}$ may affect the phase organization.

The XRD analisis of AmNO showed a well-defined crystalline phase (Figure $3 b$ ). The thermal stability of AmNO was obtained from TGA under synthetic air

Table 1. Correlation between $\mathrm{Nb}_{2} \mathrm{O}_{5} \cdot 1.8 \mathrm{H}_{2} \mathrm{O}$ LAS and BAS obtained by pyridine adsorption by FTIR analysis and the surface area obtained by BrunauerEmmett-Teller (BET) analysis

\begin{tabular}{lccc}
\hline Calcination temperature $/{ }^{\circ} \mathrm{C}$ & LAS & $($ LAS $/($ LAS + BAS $))$ & Specific surface $\operatorname{area}^{\prime}\left(\mathrm{m}^{2} \mathrm{~g}^{-1}\right)$ \\
\hline- & 1.00 & 1.00 & 150.30 \\
$115^{\circ} \mathrm{C}$ & 1.40 & 0.88 & 220.00 \\
$300{ }^{\circ} \mathrm{C}$ & 9.20 & 0.93 & 114.50 \\
\hline
\end{tabular}

LAS: Lewis-acid site; BAS: Brønsted-acid sites. 

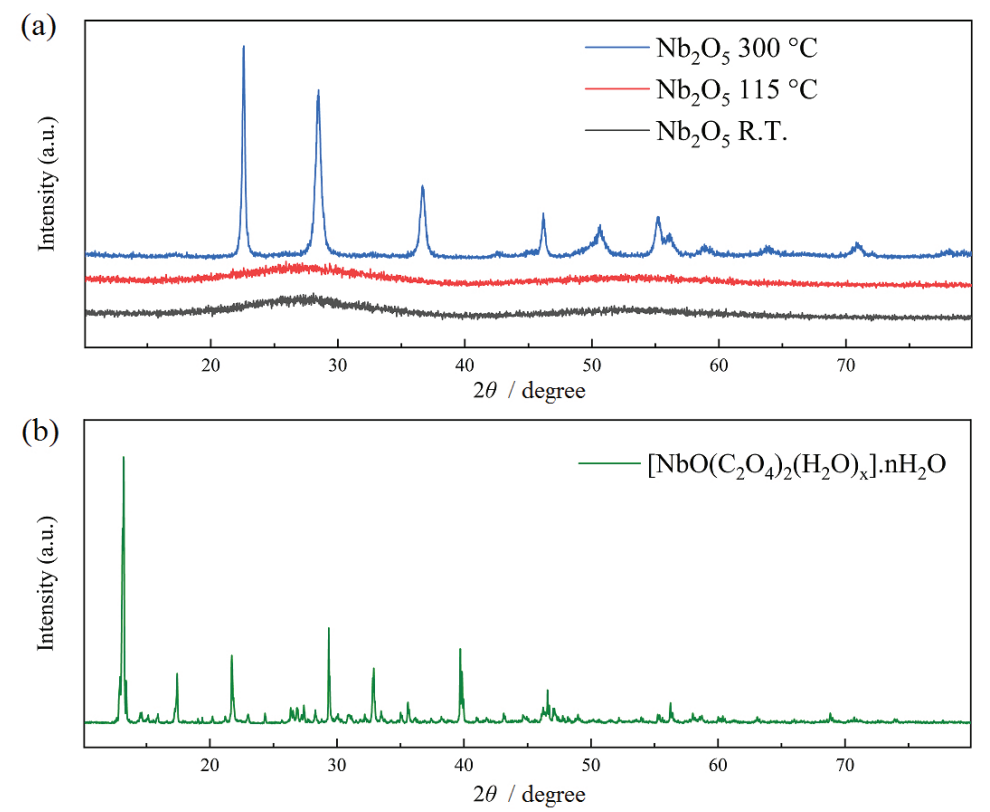

Figure 3. Ex situ X-ray diffraction under different heat treatments of (a) niobium pentoxide and (b) ammonium niobium oxalate.

atmosphere. The analysis showed several mass losses and was generally similar to that reported by Medeiros et al..$^{44}$ Loss of the adsorbed water below $70^{\circ} \mathrm{C}$ is observed and this temperature was adopted for the catalyst use to avoid any degradation. From the FTIR spectrum, it was possible to observe characteristic reference bands, such as the presence of stretching assigned to $\mathrm{N}-\mathrm{H}, \mathrm{O}-\mathrm{H}, \mathrm{C}=\mathrm{O}$ and $\mathrm{Nb}=\mathrm{O}$ bonds, and others as already reported. ${ }^{45}$

\section{Niobium pentoxide as the catalyst}

The reactions under reflux (mild conditions) using niobium pentoxide as a catalyst was divided into two groups according to the alcohol, as shown in Figure 4. For all reactions, blank experiments were performed. No conversion rate was observed in the absence of the catalyst.

From the above figure, it is possible to observe differences between all the oils' conversions. Srilatha et $_{\text {al }}{ }^{46}$ published a study on the influence of the chain length and unsaturation (presented as $\mathrm{C}_{\mathrm{n}}$ : number of unsaturation) on fatty acids esterification using methanol and $\mathrm{Nb}_{2} \mathrm{O}_{5} \cdot \mathrm{xH}_{2} \mathrm{O}$. They concluded that the reactivity decreases as the chain length and unsaturation number grows. In Figure 4 , it is possible to note that the canola oil (about $54 \%$ of $18: 1$ and $22 \%$ of $18: 2)^{47}$ with methanol, leads to higher conversion compared to soybean (20\% of $18: 1$ and $64 \%$ of $18: 2)$, sunflower (17\% of $18: 1$ and $73 \%$ of $18: 2)$ and corn (44\% of $18: 1$ and $48 \%$ of $18: 1)$. Notably, when ethanol was used, the greater conversion rate was obtained with sunflower oil transesterification. In addition, all oils' conversion rates (a)

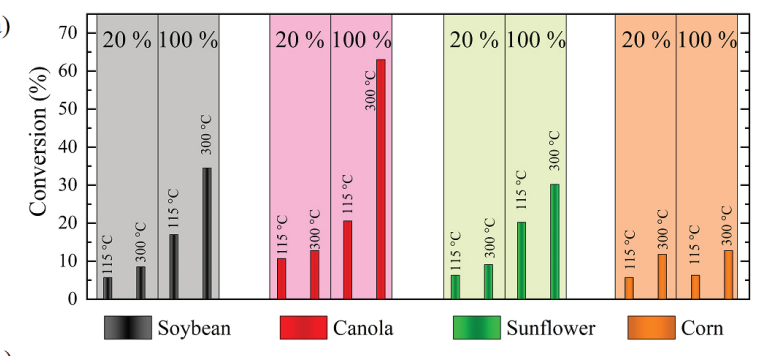

(b)

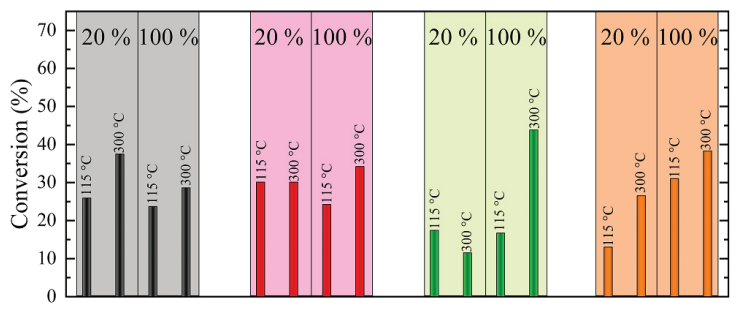

Figure 4. Conversions in (a) methyl and (b) ethyl biodiesel from soybean, canola, sunflower and corn oils using niobium pentoxide as the catalyst in a reflux system.

were about $30-40 \%$ in analogous conditions, this may be observed because of a smaller influence of calcination temperature using ethanol. Moreover, from the results with ethanol, it is not possible to observe the same effect of unsaturated fatty acids for the conversion with methanol. The conversion increases with bigger catalyst amounts as expected because of its higher availability in the system.

Our research group has previously tested the use of $\mathrm{Nb}_{2} \mathrm{O}_{5} \cdot \mathrm{xH}_{2} \mathrm{O}$ in the esterification of oleic acid (an easier reaction compared with transesterification) reaching conversions near to $82 \%$. From this, it was noted that without calcination and calcined above $300{ }^{\circ} \mathrm{C}$, the reaction was not favored..$^{37} \mathrm{~A}$ similar work in the literature describes 
the continuous production of biodiesel through the reaction between oleic acid and ethanol, using niobic acid as a solid acid catalyst at $249{ }^{\circ} \mathrm{C}$, obtaining yields of esters up to $70 \%$ and conversion up to $90 \% .{ }^{43}$ The same authors, using a packed bed tubular reactor, achieved $90 \%$ conversion with niobium phosphate as catalyst in the reaction using oleic acid and ethanol at $250{ }^{\circ} \mathrm{C} .{ }^{48}$

About our results, it is also noted that when the catalyst has its morphology changed by calcination below $300^{\circ} \mathrm{C}$, better conversions were obtained. Moreover, LAS increase seems to be vital for the catalyst activity, and it is easier to improve because of its significant decrease of the surface area (small surface area means fewer active sites available, so lower conversions are expected). From catalyst's problems such as those cited, aiming to obtain better activity, many researchers have tried to improve the catalyst's design. ${ }^{33-36,49-51}$ Studies using mixed calcium oxide and niobium oxide $\left(\mathrm{CaO}-\mathrm{Nb}_{2} \mathrm{O}_{5}\right)$ calcined at various temperatures (to produce biodiesel from palm oil and methanol) obtained conversion rates around $98 \% .{ }^{33}$ Moreover, conversion near to $89 \%$ was reported using the same mixture ratio of catalyst, 1:36 oil of macauba (Acrocomia aculeata) to methanol, and at $77{ }^{\circ} \mathrm{C}$ as reaction temperature. ${ }^{34}$ Silica pellets with a loading of $12 \% \mathrm{Nb}$ were tested by Tesser et al. ${ }^{35}$ in esterification and transesterification reaching yields around $90 \%$ using soybean oil and methanol at $180^{\circ} \mathrm{C}$. Other mixed catalysts have obtained conversions up to $90 \%$ with heating above $225^{\circ} \mathrm{C} .{ }^{36,49}$ Finally, our catalyst was shown to be easy to prepare and/or apply under milder conditions than those above, compared with other transesterification reactions.

Aiming to reduce the time and energy demand, the use of ultrasound-assisted systems has been studied. ${ }^{24-28}$ Results for the ultrasound-assisted system with soybean oil using $\mathrm{Nb}_{2} \mathrm{O}_{5} \cdot 1.8 \mathrm{H}_{2} \mathrm{O}$ are presented in Table 2. Higher conversions were observed for reactions with 4 and $6 \mathrm{~h}$ when the catalyst was used with a ratio of $100 \%$ mass of soybean oil. However, with $4 \mathrm{~h}$ and a $20 \%$ mass of catalyst, a conversion of $21.9 \%$ was obtained.

Table 2. The use of $\mathrm{Nb}_{2} \mathrm{O}_{5} .1 .8 \mathrm{H}_{2} \mathrm{O}$ under an ultrasound-assisted system with soybean oil, $60^{\circ} \mathrm{C}, 42 \mathrm{kHz}$, varying temperature and mass proportion of catalyst/oil

\begin{tabular}{lcc}
\hline time $/ \mathrm{h}$ & Mass proportion / \% & Conversion / \% \\
\hline 2 & 20 & - \\
& 100 & 16 \\
4 & 20 & - \\
& 100 & 21.9 \\
6 & 20 & 16.7 \\
\hline
\end{tabular}

Other authors reported the beneficial effects of ultrasound on biodiesel synthesis using different oils, catalysts and solvents. Stavarache et al..$^{52}$ studied the transesterification of vegetable oils with several alcohols using ultrasound of two different frequencies (28 and $40 \mathrm{kHz})$. They observed a reduction in reaction times (10-40 min), reduction in catalyst concentrations (2-3 times lower), and the quantity of required catalyst was 2 or 3 times lower. However, the frequencies influenced the reaction, higher frequencies $(40 \mathrm{kHz})$ are much more effective in the reduction of the reaction time and lower frequencies $\left(28 \mathrm{kHz}\right.$ ) gave better yields (ca. 98\%). Malani et al..$^{53}$ attained yields above $90 \%$ under optimized conditions of biodiesel production using a molar ratio of methanol:oil of $12.8: 1$, with sulfonated catalyst $(8.18 \%, \mathrm{~m} / \mathrm{m})$ at $63{ }^{\circ} \mathrm{C}$ in a single-step process. Choudhury et al.$^{54}$ reported yields of $80 \%$ of FAME in the optimum experimental conditions, i.e., alcohol to oil molar ratio (ca. 7), catalyst concentration $(6 \% \mathrm{~m} / \mathrm{m})$ at $70{ }^{\circ} \mathrm{C}$, and ultrasound frequency of $35 \mathrm{kHz}$. Other works used an ultrasound system to improve the yield of biodiesel formation, to decrease the reaction time, or only to study the ultrasonic technique in the process of transesterification or esterification of oils. ${ }^{55-58}$

From the obtained results, the study can be extended to different oils using the reaction time of $4 \mathrm{~h}$ and varying the alcohol but applying the AmNO catalyst as seen in the next topic.

\section{Ammonium niobium oxalate as the catalyst}

In the reflux system, our first behavioral study applying AmNO as the catalyst used three different times: 4, 24 and $48 \mathrm{~h}$. From those different times and varying reaction temperature and mass proportion, the conversions using soybean oil and ethanol were obtained as shown in Figure 5. The direct use of AmNO as the catalyst in transesterification has not been reported so far. Then, from the TGA analysis (Figure S4), the study was focused on reactions from 25 to $75^{\circ} \mathrm{C}$, as presented. The influence of the temperature difference was hardly observed at $4 \mathrm{~h}$. However, at $24 \mathrm{~h}$, the conversion increased to about $90 \%$ for both catalyst mass proportions. Surprisingly, the same behavior was observed for the time of $48 \mathrm{~h}$, with an increase of about $85 \%$ in both cases. From that, it is possible to imagine a time between 4 and $24 \mathrm{~h}$ wherein the influence of temperature possibly remains almost constant. In addition, for all reactions at 24 and $48 \mathrm{~h}$, the conversion increase varying only the mass of catalyst also seems to be constant (about 40\%). To conclude, catalyst mass proportions and temperature seem to be fewer influential for conversions than reaction times. 


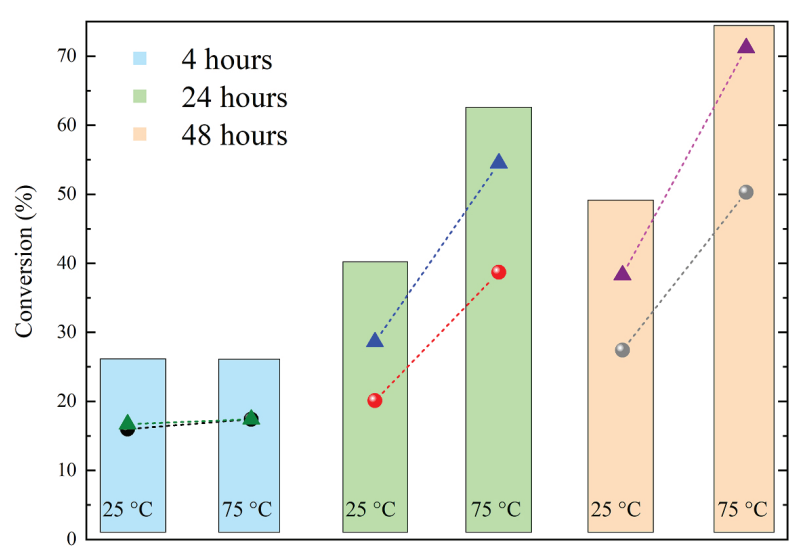

Figure 5. Conversions in ethyl biodiesel from soybean oil using ammonium niobium oxalate as the catalyst in a reflux system, varying the mass ratio (20 and $100 \%$, catalyst/oil, represented by a sphere and triangle, respectively), temperature and reaction time.

This work has a focus on the simple use of niobium catalysts due to the excellent results presented in Figure 6, tests with pure AmNO were carried out for the transesterification of soybean and canola oils, as shown in Figure 6.

As presented before, the expected chemical compositions in canola and soybean oils are different. ${ }^{47}$ Indeed, the canola oil showed better results for transesterification with methanol than with soybean oil. However, when ethanol is used instead of methanol, higher conversions are reached. Those results do not agree with the work of Stavarache et $a l .{ }^{52}$ because the use of an oil with a higher amount of unsaturation (soybean) produced the highest conversion for both alcohols, but mainly with ethanol. Many factors may explain this difference: catalyst miscibility in different solvents; activation energy, e.g., at last, the effect of increasing catalyst mass is clear for ethanol-containing reactions. This is demonstrated for soybean and canola oil, in which conversion rates increased 41.2 and $121.2 \%$, respectively. This indicates that, in general, the utilization of pure AmNO in those oils' transesterification is favored with ethanol, oils with higher unsaturation amounts, higher reaction times and bigger catalyst mass as well. Another study using this complex catalyst (but not pure) for biodiesel synthesis was reported by García-Sancho et al..$^{59}$ They used an MCM-41 silica impregnated with different amounts of niobium oxalate and obtained a yield close to $80 \%$ using sunflower oil and methanol at $200{ }^{\circ} \mathrm{C} .{ }^{59}$ Our catalyst application led to a similar conversion at a lower reaction temperature.

In Table 3, for the ultrasound-assisted system, the catalyst was AmNO varying the alcohols and the mass proportions. It is possible to observe that the best result was using soybean oil, achieving a conversion of $43.2 \%$ in the production of ethyl biodiesel. The mass ratio also proved to be determining for all cases except when using methanol and canola oil. There is a $70.1 \%$ increase in the

Table 3. Ammonium niobium oxalate under an ultrasound-assisted system with soybean, canola and linseed oils, $60^{\circ} \mathrm{C}, 42 \mathrm{kHz}, 4 \mathrm{~h}$, varying alcohol and mass proportion of catalyst/oil

\begin{tabular}{lccc}
\hline Vegetable oil & Alcohol & $\begin{array}{c}\text { Mass } \\
\text { proportion / \% }\end{array}$ & Conversion / \% \\
\hline \multirow{3}{*}{ Soybean } & methanol & 20 & - \\
& \multirow{2}{*}{ ethanol } & 100 & 8.3 \\
\cline { 2 - 4 } & \multirow{3}{*}{ methanol } & 100 & 25.4 \\
& & 20 & 43.2 \\
\cline { 2 - 4 } Canola & \multirow{2}{*}{ ethanol } & 20 & - \\
& \multirow{2}{*}{ methanol } & 100 & - \\
\hline \multirow{3}{*}{ Linseed } & & 20 & - \\
& \multirow{2}{*}{ ethanol } & 20 & - \\
& & 100 & - \\
\hline
\end{tabular}

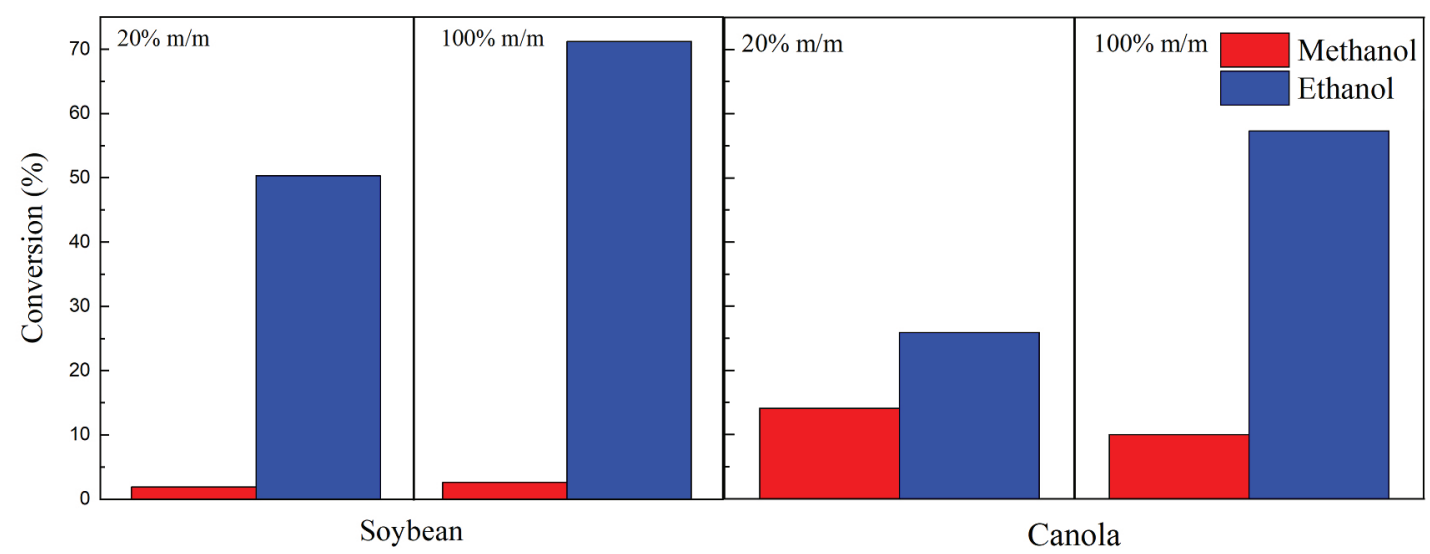

Figure 6. Conversions in biodiesel from soybean and canola oils using ammonium niobium oxalate as a catalyst in reflux system, varying the alcohol and bulk ratio of the catalyst. 
conversion of ethylic biodiesel using soybean oil with the increase in mass (\%) of catalyst used. The expectation of greater conversions with linseed oil (ca. $54 \%$ of $18: 3)^{46}$ was not observed. However, the use of an ultrasonic bath for $4 \mathrm{~h}$ and at $60{ }^{\circ} \mathrm{C}$ was promising for the production of biodiesel due to its easy handling and low energy demand.

\section{Conclusions}

$\mathrm{Nb}_{2} \mathrm{O}_{5} \cdot 1.8 \mathrm{H}_{2} \mathrm{O}$ proved to be an easily handled catalyst and with interesting conversions of vegetable oil into biodiesel. For this catalyst, the best results were obtained using a reflux system (for methyl ester synthesis), with the conversion rate increasing as the catalyst LAS and catalyst mass grows. In addition, good results were obtained using AmNO in a reflux system, as well as in the ultrasoundassisted system. For the first use so far with the AmNO catalyst, ethyl esters are favored compared with methyl esters. Finally, both catalysts were efficient on vegetable oils' transesterification under mild conditions, 1 atm, and 170 or $75^{\circ} \mathrm{C}$ for reflux system, and $60^{\circ} \mathrm{C}$ for an ultrasoundassisted system.

\section{Supplementary Information}

Supplementary information (NMR spectra and TGA analyses) is available free of charge at http://jbcs.sbq.org.br as PDF file.

\section{Acknowledgments}

The authors would like to thank Coordenação de Aperfeiçoamento de Pessoal de Nível Superior (CAPES), Fundação de Amparo à Pesquisa e Inovação do Espírito Santo (FAPES) and Conselho Nacional de Desenvolvimento Científico e Tecnológico (CNPq) for financial support and scholarships. The authors would also like to thank the Companhia Brasileira de Metalurgia e Mineração (CBMM) for catalyst donation, the Núcleo de Competências em Química do Petróleo (NCQP) and Laboratório de Materiais Carbonosos e Cerâmicos (LMC) for using their equipments.

\section{References}

1. Knothe, G.; Gerpen, J.; Krahl, J.; The Biodiesel Handbook, $2^{\text {nd }}$ ed.; Academic Press and AOCS Press: Iowa, USA, 2010.

2. Lee, A. F.; Bennett, J. A.; Manayil, J. C.; Wilson, K.; Chem. Soc. Rev. 2014, 43, 7887.

3. Mardhiah, H. H.; Ong, H. C.; Masjuki, H. H.; Lim, S.; Lee, H. V.; Renewable Sustainable Energy Rev. 2017, 67, 1225.
4. Yusuff, A. S.; Adeniyi, O. D.; Olutoye, M. A.; Akpan, U. G.; J. Appl. Sci. Process Eng. 2017, 4, 142.

5. Abdullah, S. H. Y. S.; Hanapi, N. H. M.; Azid, A.; Umar, R.; Juahir, H.; Khatoonc, H.; Enduta, A.; Renewable Sustainable Energy Rev. 2017, 70, 1040.

6. Chouhan, P. S.; Sarma, K.; Renewable Sustainable Energy Rev. 2011, 15, 4378.

7. Friend, C. M.; Xu, B.; Acc. Chem. Res. 2017, 50, 517.

8. Mansir, N.; Taufiq-yap, Y. H.; Rashid, U.; Lokman, I. M.; Energy Convers. Manage. 2017, 141, 171.

9. Melero, J. A.; Iglesias, J.; Morales, G.; Green Chem. 2009, 11, 1285.

10. Ziolek, M.; Sobczak, I.; Catal. Today 2017, 285, 211.

11. Scaldaferri, C. A.; Pasa, V. M. D.; Fuel 2019, 245, 458.

12. Méndez, F. J.; Franco-lópez, O. E.; Bokhimi, X.; Solís-Casados, D. A.; Escobar-Alarcón, L.; Klimova, T. E.; Appl. Catal., B 2017, 219, 479.

13. Tanabe, K.; Catal. Today 2003, 78, 65.

14. Nabil, Y.; Cavaliere, S.; Harkness, I. A.; Sharman, J. D. B.; Jones, D. J.; Rozière, J.; J. Power Sources. 2017, 363, 20.

15. Arpini, B. H.; Bartolomeu, A. D. A.; Andrade, C. K. Z.; da Silva-Filho, L. C.; Lacerda Jr., V.; Curr. Org. Synth. 2015, $12,1$.

16. Sowa, M.; Greń, K.; Kukharenko, A. I.; Korotin, D. M.; Michalska, J.; Szyk-Warszyńska, L.; Mosiałek, M.; Zak, J.; Pamuła, E.; Kurmaev, E. Z.; Cholakh, S. O.; Simka, W.; Mater. Sci. Eng., C 2014, 42, 529.

17. Lacerda Jr., V.; dos Santos, D. A.; da Silva-Filho, L. C.; Greco, S. J.; dos Santos, R. B.; Aldrichimica Acta 2012, 45, 19.

18. Barbosa, S. L.; Hurtado, G. R.; Klein, S. I.; Junior, V. L.; Dabdoub, M. J.; Guimarães, C. F.; Appl. Catal., A 2008, 338, 9.

19. Braga, V. S.; Barros, I. C. L.; Garcia, F. C.; Dias, S. C. L.; Dias, J.; Catal. Today 2008, 133, 106.

20. Fang, C.; Liu, Y.; Wu, W.; Li, H.; Wang, Z.; Zhao, W.; Yang, T.; Yang, S.; Waste Biomass Valorization 2019, 10, 1141.

21. Antonetti, C.; Melloni, M.; Licursi, D.; Fulignati, S.; Ribechini, E.; Rivas, S.; Carlos, J.; Cavani, F.; Maria, A.; Galletti, R.; Appl. Catal., B 2017, 206, 364.

22. Aranda, D. G.; de Goncalves, J. A.; Peres, J. S.; Ramos, A. L. D.; de Melo, C. A. R.; Antunes, O.C.; Furtado, N. C.; Taft, C.; J. Phys. Org. Chem. 2009, 22, 709.

23. Guinhos, F.; Rubim, J. C.; Suarez, P. A. Z.; J. Braz. Chem. Soc. 2009, 20, 954.

24. Vaz, L. M. O.; Martins, M. I.; Filho, U. C.; Cardoso, V. L.; Reis, M. H. M.; Environ. Prog. Sustainable Energy 2017, 36, 1262.

25. Ho, W. W. S.; Ng, H. K.; Gan, S.; Appl. Therm. Eng. 2016, 100, 553.

26. Badday, A. S.; Abdullah, A. Z.; Lee, K. T.; Khayoon, M. S.; Renewable Sustainable Energy Rev. 2012, 16, 4574.

27. Deshmane, V. G.; Gogate, P. R.; Pandit, A. B.; Ultrason. Sonochem. 2009, 16, 345. 
28. Nikseresht, A.; Daniyali, A.; Ali-Mohammadi, M.; Afzalinia, A.; Mirzaie, A.; Ultrason. Sonochem. 2017, 37, 203.

29. Brito, Y. C.; Ferreira, D. a. C.; Fragoso, D. M. D. A.; Mendes, P. R.; de Oliveira, C. M. J.; Meneghetti, M. R.; Meneghetti, S. M. P.; Appl. Catal., A 2012, 443-444, 202.

30. Rodrigues, J. A. J.; Zacharias, M. A.; Monteiro, W. R.; Pereira, A. T.; Oliveira, K. A. de; Monteiro, R. de S.; WO pat. 20060451692006 (CA 04B35/495).

31. Anuar, M. R.; Abdullah, A. Z.; Appl. Catal., A 2016, 514, 214.

32. Veljković, V. B.; Avramović, J. M.; Stamenković, O. S.; Renewable Sustainable Energy Rev. 2012, 16, 1193.

33. Wong, Y. C.; Tan, Y. P.; Taufiq-Yap, Y. H.; Ramli, I.; Sains Malays. 2014, 43, 783.

34. Cubides-Román, D. C.; Constantino, A. F.; David, G. F.; Martins, L. F.; dos Santos, R. B.; Romão, W.; Neto, A. C.; Lacerda Jr., V.; J. Braz. Chem. Soc. 2019, 30, 562.

35. Tesser, R.; Vitiello, R.; Carotenuto, G.; Sancho, C. G.; Vergara, A.; Torres, P. J. M.; Li, C.; Di Serio, M.; Catal. Sustainable Energy 2015, 1, 33.

36. Portilho, M.; Vidal Vieira, J. A.; Zotin, J. L.; Lima, M. S. S.; US pat. $2008295393 A 12008$ (CA 44/308).

37. dos Santos, D. A.; Lacerda Jr., V.; Rocha, J. T. C.; dos Santos, R. B.; Greco, S. J.; Neto, A. C.; Silva, R. C.; de Castro, E. V. R.; Mod. Res. Catal. 2013, 2, 63.

38. Gelbard, G.; Brès, O.; Vargas, R. M.; Vielfaure, F.; Schuchardt, U. F.; J. Am. Oil Chem. Soc. 1995, 72, 1239.

39. Brunauer, S.; Emmett, P. H.; Teller, E.; J. Am. Chem. Soc. 1938, 60, 309.

40. Lowell, S.; Schields, J. E.; Thomas, M. A.; Thommes, M.; Characterization of Porous Solids and Powders: Surface Area, Pore Size and Density; Kluwer Academic Publishers: Dordrecht, Netherlands, 2004.

41. Nowak, I.; Ziolek, M.; Chem. Rev. 1999, 99, 3603.

42. Mendes, F. M. T.; Perez, C. A.; Soares, R. R.; Noronha, F. B.; Schmal, M.; Catal. Today 2003, 78, 449.

43. Rade, L. L.; Lemos, C. O. T.; Barrozo, M. A. S.; Ribas, R. M.; Monteiro, R. S.; Hori, C. E.; Renewable Energy 2018, 115, 208.

44. Medeiros, F. F. P.; Moura, M. F. V.; da Silva, A. G. P.; Souza, C. P.; Gomes, K. K. P.; Gomes, U. U.; Braz. J. Chem. Eng. 2006, 23,531 .
45. Su, T.; Zhai, Y.; Jiang, H.; Gong, H.; J. Therm. Anal. Calorim. 2009, 98, 449.

46. Srilatha, K.; Lingaiah, N.; Prasad, P. S. S.; Devi, B. L. A. P.; Prasad, R. B. N.; Venkateswar, S.; Ind. Eng. Chem. Res. 2009, 48, 10816.

47. Gunstone, F. D.; Vegetable Oils in Food Technology: Composition, Properties and Uses; Blackwell Publishing Ltd, Oxford, UK, 2002.

48. Rade, L. L.; Lemos, C. O. T.; Barrozo, M. A. S.; Ribas, R. M.; Monteiro, R. S.; Hori, C. E.; Renewable Energy 2019, 131, 348.

49. Policano, M. D.; Rivaldi, J. D.; De Castro, H. F.; Carneiro, L. M.; Int. J. Eng. Res. Sci. 2016, 2, 2395.

50. Sturt, N. R. M.; Vieira, S. S.; Moura, F. C. C.; J. Environ. Chem. Eng. 2019, 7, 102866.

51. Trejda, M.; Nurwita, A.; Kryszak, D.; Microporous Mesoporous Mater. 2019, 278, 115.

52. Stavarache, C.; Vinatoru, M.; Nishimura, R.; Maeda, Y.; Ultrason. Sonochem. 2005, 12, 367.

53. Malani, R. S.; Sardar, H.; Malviya, Y.; Goyal, A.; Moholkar, V. S.; Ind. Eng. Chem. Res. 2018, 57, 14926.

54. Choudhury, H. A.; Pratim, P.; Malani, R. S.; Moholkar, V. S.; Ultrason. Sonochem. 2014, 21, 1050.

55. Ahmed, H.; Malani, R. S.; Moholkar, V. S.; Chem. Eng. J. 2013, $231,262$.

56. Kalva, A.; Sivasankar, T.; Moholkar, V. S.; Kalva, A.; Sivasankar, T.; Moholkar, V. S.; Ind. Eng. Chem. Res. 2009, 48, 534.

57. Stavarache, C.; Vinatoru, M.; Nishimura, R.; Maeda, Y.; Ultrason. Sonochem. 2005, 12, 367.

58. Stavarache, C.; Vinatoru, M.; Maeda, Y.; Ultrason. Sonochem. 2007, 14, 380.

59. García-Sancho, C.; Moreno-Tost, R.; Mérida-Robles, J. M.; Santamaría-González, J.; Jiménez-López, A.; Maireles-Torres, P.; Appl. Catal., B 2011, 108-109, 161.

Submitted: February 21, 2019

Published online: May 20, 2019 